\title{
Spatial and temporal dynamics of reproduction and settlement in the Pompeii worm Alvinella pompejana (Polychaeta: Alvinellidae)
}

\author{
Baptiste Faure $^{1, *}$, Pierre Chevaldonné ${ }^{2}$, Florence Pradillon ${ }^{3}$, Eric Thiébaut ${ }^{1}$, \\ Didier Jollivet $^{1}$
}

\begin{abstract}
${ }^{1}$ Station Biologique de Roscoff, UMR 714CNRS - Université Pierre \& Marie Curie-Paris 6, Adaptation et diversité en milieu marin, B.P. 74, Place Georges Teissier, 29682 Roscoff Cedex, France

${ }^{2}$ Station Marine d'Endoume, Centre d'Océanologie de Marseille, UMR 6540 CNRS - Université Méditerranée, Diversité, Evolution et Ecologie Fonctionnelle Marine, Rue de la Batterie des Lions, 13007 Marseille, France

${ }^{3}$ Université Pierre et Marie Curie-Paris 6,UMR 7138 CNRS-UPMC-MNHN-IRD, Systématique, Adaptation et Evolution,
\end{abstract} 7 quai Saint-Bernard, 75252 Paris Cedex 05, France

\begin{abstract}
The tubicolous polychaete Alvinella pompejana (Desbruyères \& Laubier) inhabits deepsea hydrothermal vents. To assess its reproductive and recruitment strategies in response to such extreme conditions, populations of $A$. pompejana were sampled at various spatial scales: among hydrothermal vents within the $13^{\circ} \mathrm{N} /$ East Pacific Rise vent field and among vent sectors along the southern East Pacific Rise. Additional samples were collected at 1 vent $31 \mathrm{~d}$ apart to determine shortterm temporal variations. Such a sampling strategy allowed us to conduct an integrated study of both the spatial variation of the reproductive dynamics (i.e. fecundity, oocyte distribution) and the population structure of this polychaete. Despite a 1:1 sex ratio for each population, a male-biased sex ratio was found at sexual maturity, which could maximise reproductive success in this spermathecaebearing species. Oocyte size distributions in mature females distinguished 5 maturity stages related to the presence of 1 to 5 distinct oocyte size groups. Coelomic fecundity, which is among the highest known in polychaetes (max. 978000 oocytes), depends on the maturity stage, but not on the size of the female. The analysis of oocyte distributions strongly highlighted that reproduction is semicontinuous. Mature oocytes are however discretely recruited in the gonoducts from a massive stock of coelomic oogonia and spawned in pulses that may be synchronised between reproductive females. Size-frequency distributions of organisms displayed polymodal structure, suggesting discontinuous recruitment that may be locally affected by the vent dynamics or variations in larval supply. The discrepancy between semi-continuous reproduction and a polymodal size-frequency distribution may be explained by: (1) a limited amount of recruits within populations, (2) rapid growth during the early benthic phase, and/or (3) an accumulation of individuals of different ages in the adult cohort. Nearly continuous production of gametes and storage of mature oocytes and/or sperm seem to be a general trend selected in hydrothermal-vent polychaete species.
\end{abstract}

KEY WORDS: Hydrothermal vents - Sex ratio - Oogenesis - Semi-continuous reproduction . Population structure $\cdot$ East Pacific Rise

Resale or republication not permitted without written consent of the publisher

\section{INTRODUCTION}

Reproduction mode is a crucial element of population dynamics on which recruitment efficiency, population growth rate, or extinction rate directly depend.
Generally speaking, continuous recruitment implies continuous reproduction, while discontinuous recruitment often implies discontinuous but synchronised reproduction. Polychaete annelids display a large variety of reproduction modes due to the simplicity and the 
great phenotypic plasticity of their reproductive system and also to their adaptive ability to live in contrasting marine habitats (Wilson 1991, Giangrande 1997). According to the interaction between environmental factors and reproduction, polychaetes can be divided into 4 main reproductive patterns (Olive 1984): (1) semelparous species that breed only once during their life, with a high degree of intra-population synchrony and reproduction highly controlled by endogenous factors; (2) iteroparous species that reproduce more than once during their life time, but at an annual interval, with a high degree of within-population synchrony; in these forms, reproduction is governed by a coupling between internal and external factors; (3) iteroparous species with no within-population synchrony and reproduction controlled by endogenous factors; and (4) semi-continuous species with continuous reproduction where short-term intra-population synchrony may be found.

Polychaete reproduction is even more intricate as gametogenesis may be more or less rapid according to species (Eckelbarger 1983). While vitellogenesis is often slow and takes a few months for most semelparous or iteroparous species, it can be fast and achieved in $<2 \mathrm{wk}$ for semi-continuous or continuous breeders. Furthermore, gamete size and the way gametes are produced and emitted are also very diverse. Although polychaetes usually exhibit external fertilisation, some use internal fertilisation with or without sperm storage (Zal et al. 1994, Jollivet et al. 2000, Pradillon \& Gaill 2003). Egg size and gamete mating appear to be under great phylogenetic, morphological and ecological constraints. As observed for numerous polychaete families, species of small size are not able to invest as much energy in egg production in a single breeding episode as a species of larger size, and exhibit lower fecundity, larger oocytes and generally a continuous reproduction pattern (Schroeder \& Hermans 1975, McHugh 1993). While life-history traits may be the direct evolutionary consequence of selective pressures, total fecundity or egg size are also influenced by ecological factors such as 'patch' size and feeding resources associated with a given habitat. This is particularly relevant for harsh marine environments like deep-sea hydrothermal vents where environmental conditions are 'extreme' and highly variable.

Rapid changes in the faunal composition of hydrothermal-vent communities are the reflection of the high instability of the vent emissions and the great level of habitat patchiness (Copley et al. 1997, Shank et al. 1998, Sarrazin et al. 1999). Hydrothermal vents are often extremely dynamic, which can lead to population extinctions associated with recurrent colonisations of the new emergent emissions (Jollivet 1996). Such spatio-temporal variability may thus have a profound impact on the organism life-history traits and over time could have promoted specific adaptive modes of reproduction and dispersal in vent animals. Only few studies have been conducted on the reproductive and recruitment strategies of hydrothermal-vent polychaetes. They have focused either on families known from other marine environments (e.g. Ampharetidae, Polynoidae) (McHugh 1989, McHugh \& Tunnicliffe 1994, Jollivet et al. 2000) or on endemic families such as Alvinellidae or Siboglinidae (Zal et al. 1995, Copley et al. 1999, Thiébaut et al. 2002, Pradillon et al. 2005). They all showed peculiar adaptive convergence on reproductive mode and larval development. Indeed, most of them display continuous oogenesis (McHugh 1989, Copley et al. 2003, Pradillon et al. 2005), organs for oocyte storage with spermathecae and thus internal fertilisation of oocytes (Zal et al. 1994, Jollivet et al. 2000, Hilario et al. 2005). These species are also characterised by a high fecundity relative to their body size and produce mature oocytes of great size consistent with the hypothesis of lecithotrophic or direct development (McHugh \& Tunnicliffe 1994, Zal et al. 1995, Jollivet et al. 2000).

Living on hydrothermal vent chimneys throughout the East Pacific Rise (EPR) from $32^{\circ} \mathrm{S}$ to $21^{\circ} \mathrm{N}$, the Pompeii worm Alvinella pompejana has certainly been one of the most studied species over the last few years in terms of reproductive biology and population structure. It is a gonochoric species with extra-ovarian gametogenesis (Pradillon \& Gaill 2003). During pairing, sperm is transferred and stored inside females within spermathecae after pseudocopulation. This mode of sperm transfer is thought to increase the mating probability of gametes, and thus reproductive success (Zal et al. 1994). According to egg size, development is supposed to be lecithotrophic or direct, although larval stages have never been collected. Thus, its reproductive system, egg size and sperm morphology are more consistent with restricted dispersal capabilities (Chevaldonné et al. 1997, Jollivet et al. 1999). However, its reproduction and recruitment dynamics remain poorly documented because of small sample sizes and sampling coverage, lack of temporal series of collections, and inability to keep animals alive after recovery on board. Recently, only 1 study showed different stages of female maturity within single local samples, therefore suggesting continuous gametogenesis at the scale of a local population (Pradillon et al. 2005). Conversely, A. pompejana shows signs of the polymodal population structure associated with discontinuous recruitment that suggest the synchrony of individuals for at least 1 stage of the life cycle (Jollivet 1993).

To better understand how reproduction and recruitment dynamics affect population persistence of polychaetes associated with highly instable and fragmented 
hydrothermal habitats, the aims of the present study are: (1) to describe the successive stages of Alvinella pompejana reproduction dynamics, (2) to assess the relationships between reproductive and recruitment patterns over different spatial scales (local vs. regional scale) and (3) to appreciate short-term variations in oocyte and individual sizes. This work uses statistical analyses performed on demographic and reproductive structures of $A$. pompejana coming from a large series of samples collected over both the northern East Pacific Rise (NEPR) and the southern East Pacific Rise (SEPR).

\section{MATERIALS AND METHODS}

Study area and sampling. Samples of the deep-sea hydrothermal vent polychaete Alvinella pompejana were collected during 3 oceanographic cruises, Hot'96 (February to March 1996), Phare'02 (April to June 2002) and Biospeedo'04 (April to May 2004), on board the RV 'Nadir' and RV 'Atalante' with the hydraulic arm of either the manned French submersible 'Nautile' (Hot'96 and Biospeedo'04) or the French ROV 'VICTOR6000'
(Phare'02). After collection, all worms were placed into an insulated basket until they reached the surface. The number of individuals collected and the vent locality's coordinates for of each sample are presented in Table 1.

During the Phare'02 cruise, Alvinella pompejana samples were collected at a local scale over several vent chimneys from 6 vent sites 0.1 to $4 \mathrm{~km}$ distant from each other at $13^{\circ} \mathrm{N} / \mathrm{EPR}$ (Fig. 1). During the Biospeedo'04 cruise, sampling was performed at a regional scale from 8 disjunctive hydrothermal vent sectors that were 2 to $1650 \mathrm{~km}$ distant from each other over a large portion of the SEPR (Fig. 1). Two successive collections of A. pompejana were conducted on a single hydrothermal vent chimney at the Totem vent site $\left(13^{\circ} \mathrm{N} /\right.$ EPR) (Fig. 1) during the Hot'96 cruise. The worms were sampled in the same assemblage, at the same exact location, $31 \mathrm{~d}$ apart, to estimate changes in individual size and reproductive stages over a short time scale.

Habitat characteristics of Alvinella pompejana have recently been described by Desbruyères et al. (1998).

Biometry and sex ratio. After recovery on board, the gender of specimens was identified by observation of the genital pore, which is wider for females than for

Table 1. Alvinella pompejana. Date of collection, location and size of samples collected from vent chimneys at the northern and southern East Pacific Rise

\begin{tabular}{|c|c|c|c|c|}
\hline Oceanographic survey & Name & Date & Location & Sample size \\
\hline \multicolumn{5}{|c|}{ Northern East Pacific Rise } \\
\hline \multirow[t]{2}{*}{ Hot'96 } & Totem & 16 Feb 1996 & $12^{\circ} 48.80^{\prime} \mathrm{N}, 103^{\circ} 56.500^{\prime} \mathrm{W}$ & 48 \\
\hline & & 18 Mar 1996 & $12^{\circ} 48.80^{\prime} \mathrm{N}, 103^{\circ} 56.500^{\prime} \mathrm{W}$ & 64 \\
\hline Total & & & & 112 \\
\hline \multirow[t]{15}{*}{ Phare'02 } & Elsa & 21 May 2002 & $12^{\circ} 48.143^{\prime} \mathrm{N}, 103^{\circ} 56.307^{\prime} \mathrm{W}$ & 5 \\
\hline & & 26 May 2002 & $12^{\circ} 48.143^{\prime} \mathrm{N}, 103^{\circ} 56.307^{\prime} \mathrm{W}$ & 39 \\
\hline & & 29 May 2002 & $12^{\circ} 48.143^{\prime} \mathrm{N}, 103^{\circ} 56.307^{\prime} \mathrm{W}$ & 38 \\
\hline & Genesis & 25 May 2002 & $12^{\circ} 48.641^{\prime} \mathrm{N}, 103^{\circ} 56.442^{\prime} \mathrm{W}$ & 63 \\
\hline & Julie & 25 May 2002 & $12^{\circ} 49.058^{\prime} \mathrm{N}, 103^{\circ} 56.571^{\prime} \mathrm{W}$ & 121 \\
\hline & & 28 May 2002 & $12^{\circ} 49.058^{\prime} \mathrm{N}, 103^{\circ} 56.571^{\prime} \mathrm{W}$ & 5 \\
\hline & Jumeaux & 30 May 2002 & $12^{\circ} 48.646^{\prime} \mathrm{N}, 103^{\circ} 56.436^{\prime} \mathrm{W}$ & 103 \\
\hline & Pulsar & 27 May 2002 & $12^{\circ} 49.842^{\prime} \mathrm{N}, 103^{\circ} 56.802^{\prime} \mathrm{W}$ & 40 \\
\hline & Parigo & 19 May 2002 & $12^{\circ} 48.589^{\prime} \mathrm{N}, 103^{\circ} 56.423^{\prime} \mathrm{W}$ & 36 \\
\hline & & 20 May 2002 & $12^{\circ} 48.589^{\prime} \mathrm{N}, 103^{\circ} 56.423^{\prime} \mathrm{W}$ & 9 \\
\hline & & 22 May 2002 & $12^{\circ} 48.589^{\prime} \mathrm{N}, 103^{\circ} 56.423^{\prime} \mathrm{W}$ & 6 \\
\hline & & 23 May 2002 & $12^{\circ} 48.589^{\prime} \mathrm{N}, 103^{\circ} 56.423^{\prime} \mathrm{W}$ & 1 \\
\hline & & 25 May 2002 & $12^{\circ} 48.589^{\prime} \mathrm{N}, 103^{\circ} 56.423^{\prime} \mathrm{W}$ & 4 \\
\hline & & 26 May 2002 & $12^{\circ} 48.589^{\prime} \mathrm{N}, 103^{\circ} 56.423^{\prime} \mathrm{W}$ & 5 \\
\hline & & 29 May 2002 & $12^{\circ} 48.589^{\prime} \mathrm{N}, 103^{\circ} 56.423^{\prime} \mathrm{W}$ & 16 \\
\hline Total & & & & 491 \\
\hline \multicolumn{5}{|c|}{ Southern East Pacific Rise } \\
\hline \multirow[t]{8}{*}{ Biospeedo'04 } & Last Hope & 10 Apr 2004 & $7^{\circ} 25.451^{\prime} \mathrm{S}, 107^{\circ} 47.702^{\prime} \mathrm{W}$ & 32 \\
\hline & Lucky Eric & 4 May 2004 & $13^{\circ} 59.209^{\prime} \mathrm{S}, 112^{\circ} 28.956^{\prime} \mathrm{W}$ & 57 \\
\hline & Rehu Marka & 24 Apr 2004 & $17^{\circ} 24.964^{\prime} \mathrm{S}, 113^{\circ} 12.128^{\prime} \mathrm{W}$ & 93 \\
\hline & Nadir & 30 Apr 2004 & $17^{\circ} 25.891^{\prime} \mathrm{S}, 113^{\circ} 12.365^{\prime} \mathrm{W}$ & 17 \\
\hline & Calvin & 28 Apr 2004 & $17^{\circ} 35.806^{\prime} \mathrm{S}, 113^{\circ} 14.888^{\prime} \mathrm{W}$ & 86 \\
\hline & Fromveur & 21 Apr 2004 & $18^{\circ} 25.964^{\prime} \mathrm{S}, 113^{\circ} 23.349^{\prime} \mathrm{W}$ & 132 \\
\hline & Near Jasmine & 15 Apr 2004 & $21^{\circ} 25.295^{\prime} \mathrm{S}, 114^{\circ} 16.465^{\prime} \mathrm{W}$ & 46 \\
\hline & Krasnov & 14 Apr 2004 & $21^{\circ} 33.604^{\prime} \mathrm{S}, 114^{\circ} 17.884^{\prime} \mathrm{W}$ & 32 \\
\hline Total & & & & 495 \\
\hline
\end{tabular}




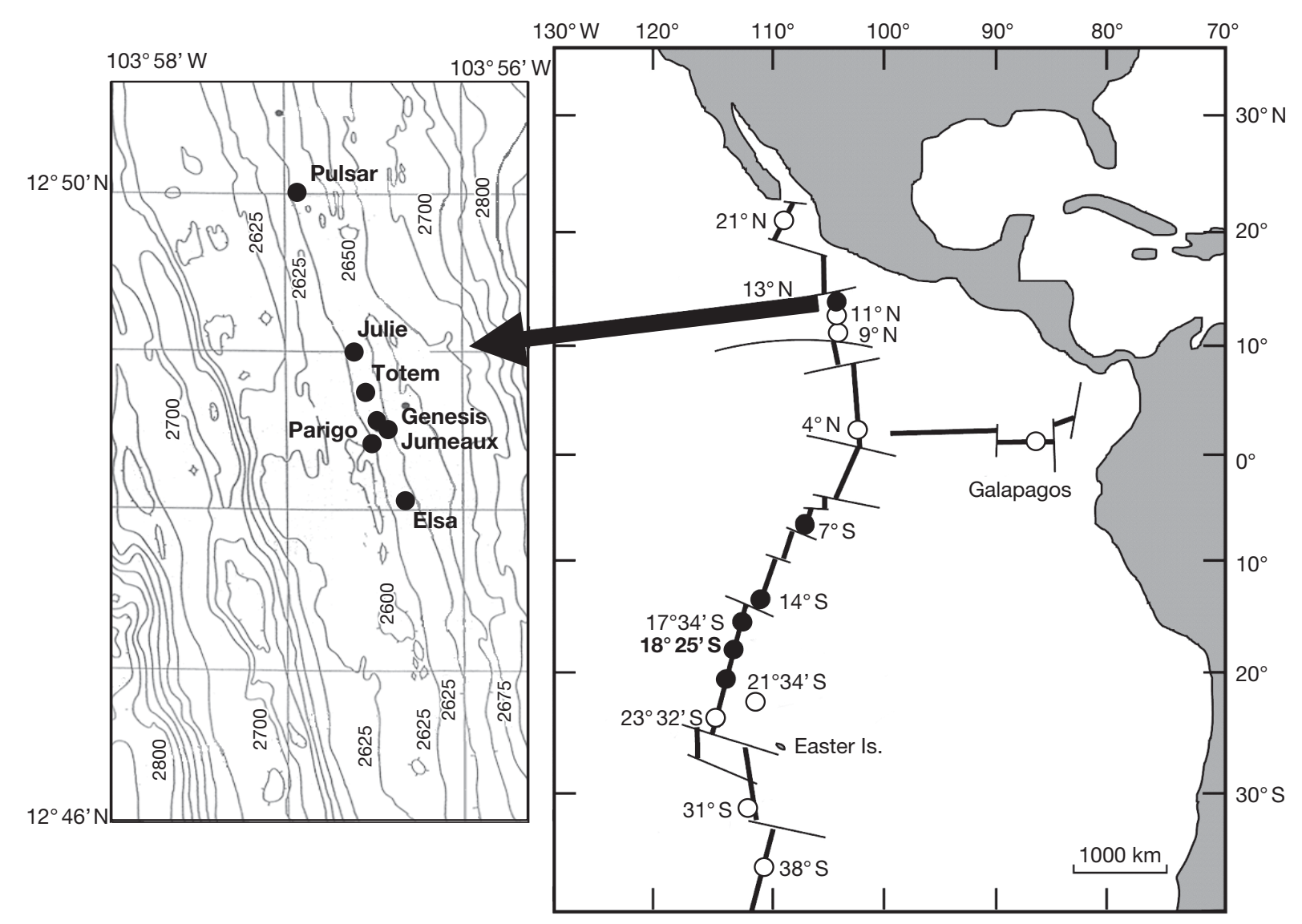

Fig. 1. Sampling sites for the deep-sea Alvinella pompejana worms used in our study (isobaths in m). O: hydrothermal vent; 0: sampling sites. The $13^{\circ} \mathrm{N}$ region is magnified

males (Pradillon \& Gaill 2003). To analyse demographic structure, the dorsal width of the 4th setigerous segment (S4) was used as an index of the individual size as previously shown by Jollivet (1993): $\log ($ width $)=2.45+0.32 \log ($ dry weight $)(n=30, r=$ 0.96). The S4 segment is easily recognisable when sizing individuals, and is conveniently very rigid due to the presence of a large pair of hooks. All measurements were made to the nearest $0.05 \mathrm{~mm}$ using a calliper under a binocular microscope. The smallest individuals $(<3 \mathrm{~mm} \mathrm{S4}$ width) were not easily and definitively assigned to a gender and have therefore been considered juveniles.

Sexual maturity, female fecundity and oocyte measurements. For each female, coelomic fluid was carefully removed by making a ventral incision to the body wall of the trunk to release the fluid following the recommendations of Olive (1970). Specimens were then cut open along the anterior-posterior axis, from the end of the body to the first setigerous segment. The body cavity was extensively washed out in order to collect all coelomic oocytes. The coelomic fluid with oocytes of each mature female was resuspended in
$50 \mathrm{ml}$ of a solution of $3 \%$ borate-buffered formalin in seawater. Oocytes (oogonia to mature oocyte) were counted from 2 oocyte suspension aliquots of $0.25 \mathrm{ml}$. In addition, spermiducts were also dissected on males collected during Biospeedo'04 and checked for sperm in order to discriminate mature males and assess their size of first sexual maturity. In this study, the term 'mature female' was used for females undergoing oocyte maturation in the coelom but not yet able to reproduce, whereas the term 'reproductive female' was restricted to females displaying mature oocytes inside gonoducts. 'Immature females' correspond to females without any genital product.

Due to the discoid shape of oocytes, the maximum oocyte diameter crossing the micropyle was the only measurement taken into account. For females collected during the Hot'96 and Phare'02 cruises, the maximum diameter was measured using a microscope with a Spot video camera (Diagnostic Instrument Inc, Version 3 for Windows) from a subsample of 200 oocytes. This technique enabled us to digitise oocytes and then to measure their diameter after calibration (with an error of $2 \mu \mathrm{m}$ ). For Biospeedo'04 
samples, maximum oocyte diameters were measured to the nearest $5 \mu \mathrm{m}$ using an eye-piece micrometer under a Leitz inverted microscope from a subsample of 200 oocytes.

Size-frequency histograms. S4 size-frequency histograms have been produced for each sample and each gender, while oocyte size-frequency histograms have been drawn for each mature female. The class interval (1 $\mathrm{mm}$ for S4 size and $10 \mu \mathrm{m}$ for oocytes) was chosen in order to minimise the number of null classes and to take into account the measurement error (Jollivet 1993). All size-frequency histograms were then smoothed using a moving average of 3 classes to rule out non-significant peaks (Frontier \& Pichod-Viale 1998). Modal decomposition of size-frequency histograms was done according to the method of Bhattacharya (1967). Mean sizes, SDs and proportions of each identified Gaussian component were then refined using the MIX 3.1 program package (Ichthus Data System; MacDonald \& Green 1988). This method provides the best fit between theoretical admixtures of normal distributions and the observed one, by the maximum likelihood method.

We chose to use modal decomposition for the oocyte distribution, which, in most cases, resembles a lognormal distribution, in order to have an objective element to describe the stage of oocyte maturation. Because preliminary analyses showed nearly identical standard deviations between oocyte size groups within and between distributions of the 98 mature females, a second series of MIX decompositions was performed on the same histograms assuming equal modal variances under the assumption of constant oocyte maturation rate, which has been widely reported for polychaetes (Zal et al. 1995).

Statistical analyses. For each collected sample, several population descriptors have been calculated as follows: (1) sex ratio, (2) the proportion of mature males and females in the sample, (3) the proportion of oocyte maturation stages in the female population and (4) the size at first sexual maturity in males and females.

Departure from a sex ratio of 1:1 was tested for each sample and for each cruise collection using a standard $\chi^{2}$ goodness-of-fit-test.

Size-frequency distributions between males and females from NEPR and SEPR, or between NEPR and SEPR for all individuals were compared using a standard Kolmogorov-Smirnov 2-sample test. Recruitment synchronisation within the $13^{\circ} \mathrm{N} / \mathrm{EPR}$ vent field was evaluated using a Kruskal-Wallis test, because of the small sample sizes. Results were evaluated by comparing sample distributions. For the SEPR samples of larger size, mean sizes among vent sectors were compared using 1-way ANOVA with S4 size as the variable and vent sector as the fixed factor for each size group. For each modal component, the variance within groups was calculated as the average of the variances within each sector, weighted by its $\mathrm{df}_{\text {, whereas the }}$ variance among groups was estimated from the variance of means among sectors (Sokal \& Rohlf 1995).

Synchronisation of oocyte maturation across vent sites $\left(13^{\circ} \mathrm{N} / \mathrm{EPR}\right)$ or across vent sectors (SEPR) was tested by performing 1-way ANOVAs for the first 2 oocyte modal components using the site or sector as a fixed factor and modal values of the spatial samples as the variable. Only the first 2 cohorts were chosen for these analyses, because they represented the cohorts with the highest proportions of oocytes and because most of the females presented at least these 2 cohorts. Within a vent or a sector, synchronisation of oocyte maturation was analysed using a 1-way ANOVA, with females as a random factor and oocyte size as a variable. A multiple linear regression was performed to test for size, latitudinal and time effects on the mode of the first oocyte cohorts. The significance of partial regression coefficients was tested by permutations according to Anderson \& Legendre (1999).

To assess short-term changes in population structure and gametogenesis at the Totem site in 1996, modal sizes of individuals and modal diameter of oocytes were compared across a short time interval using a Student's $t$-test.

\section{RESULTS}

\section{Population structure in Alvinella pompejana}

Sex ratio, male and female distributions, and size at first sexual maturity

During Phare'02, 491 individuals were sampled on several vent chimneys at $13^{\circ} \mathrm{N} / \mathrm{EPR}$. The relative proportions of juveniles and the proportion of males and females, together with their average size, are presented in Table 2. In spite of the environmental instability of vent sites and the fragmentation of the habitat, there is no significant departure from a 1:1 sex ratio for either a given sample or the whole worm collection $\left(\chi^{2}\right.$ test; $\left.\mathrm{p}>0.05\right)$. Only $7.5 \%$ of the whole collection corresponds to individuals too small to be sexed (S4 width $<3 \mathrm{~mm}$ ) and referred to as juveniles. The minimum size at which females reached their first sexual maturity corresponds to an S4 width of $6 \mathrm{~mm}$.

During the Biospeedo'04 cruise, 495 ind. were sampled, sexed and measured (Table 2). The observed sex ratio in this collection was not found to be different from the expected value of $1: 1 \quad\left(\chi^{2}\right.$ test $\left.t_{i} p>0.05\right)$, although 2 samples departed significantly from this expectation at the $17^{\circ} 24^{\prime}$ and $21^{\circ} 33^{\prime} \mathrm{S}$ vent sectors. 
Table 2. Alvinella pompejana. Sex ratio and average size of males (m), females (f) and juveniles (j) in samples collected at the northern $\left(13^{\circ} \mathrm{N}\right)$ and southern East Pacific Rise (EPR) during the Phare'02 and Biospeedo'04 cruises. A $\chi^{2}$ test was used to compare observed and expected numbers of males and females under the null hypothesis of gender equality $(1: 1)$. ${ }^{*} \mathrm{p}<0.05$ (sex ratios with no asterisk are not significant); S4: 4th setigerous segment

\begin{tabular}{|c|c|c|c|c|c|c|c|c|c|c|c|c|c|c|}
\hline \multirow[t]{2}{*}{ Vent site } & \multicolumn{4}{|c|}{$\begin{array}{l}\text { Number of } \\
\text { individuals }\end{array}$} & \multicolumn{3}{|c|}{$\begin{array}{c}\text { Number of } \\
\text { mature } \\
\text { individuals }\end{array}$} & \multicolumn{2}{|c|}{$\begin{array}{c}\text { Proportion of } \\
\text { mature } \\
\text { individuals }\end{array}$} & \multicolumn{3}{|c|}{$\begin{array}{l}\mathrm{S} 4 \text { width } \\
\text { mean (mm) }\end{array}$} & \multicolumn{2}{|c|}{$\begin{array}{l}\mathrm{S} 4 \text { width } \\
\text { mean of mature } \\
\text { individuals }(\mathrm{mm})\end{array}$} \\
\hline & $\mathrm{m}$ & $\mathrm{f}$ & j & $\begin{array}{c}\text { Sex ratio } \\
\wp / 0^{1}\end{array}$ & $\mathrm{~m}$ & $\mathrm{f}$ & $\begin{array}{c}\text { Sex ratio } \\
\wp / 0^{7}\end{array}$ & $\mathrm{~m}$ & $\mathrm{f}$ & $\mathrm{m}$ & f & $\begin{array}{l}\text { ind. } \\
\text { mean }\end{array}$ & $\mathrm{m}$ & f \\
\hline \multicolumn{15}{|l|}{ Northern EPR } \\
\hline Elsa (pooled) & 41 & 34 & 7 & 1.21 & & 8 & & & 0.24 & 5.67 & 5.85 & & & 7.57 \\
\hline Genesis & 31 & 32 & 0 & 0.97 & & 12 & & & 0.37 & 5.40 & 5.92 & & & 7.56 \\
\hline Julie & 59 & 56 & 11 & 1.05 & & 13 & & & 0.23 & 4.39 & 4.59 & & & 7.01 \\
\hline Jumeaux & 45 & 44 & 14 & 1.02 & & 6 & & & 0.14 & 5.63 & 6.31 & & & 8.73 \\
\hline Pulsar & 20 & 15 & 5 & 1.33 & & 2 & & & 0.13 & 5.78 & 6.37 & & & 8.40 \\
\hline Parigo & 37 & 40 & 0 & 0.90 & & 10 & & & 0.25 & 6.57 & 6.86 & & & 6.55 \\
\hline Total Phare'02 & 233 & 221 & 37 & 1.05 & & 51 & & & 0.23 & 5.57 & 5.98 & & & 8.36 \\
\hline \multicolumn{15}{|l|}{ Southern EPR } \\
\hline $7^{\circ} 25^{\prime} \mathrm{S}$ & 16 & 16 & 0 & 1.00 & 9 & 5 & $1.80^{*}$ & 0.56 & 0.31 & 6.25 & 5.96 & 6.13 & 6.79 & 7.71 \\
\hline $13^{\circ} 58^{\prime} \mathrm{S}$ & 22 & 27 & 8 & 0.81 & 5 & 4 & $1.25^{*}$ & 0.23 & 0.15 & 4.67 & 5.23 & 4.78 & 8.13 & 8.80 \\
\hline $17^{\circ} 24^{\prime} \mathrm{S}$ & 52 & 41 & 0 & $1.27^{*}$ & 13 & 16 & $0.81^{*}$ & 0.25 & 0.39 & 6.21 & 6.69 & 6.42 & 7.80 & 7.48 \\
\hline $17^{\circ} 25^{\prime} \mathrm{S}$ & 9 & 8 & 0 & 1.13 & 6 & 3 & $2.00^{*}$ & 0.67 & 0.38 & 5.76 & 7.23 & 6.40 & 6.89 & 9.93 \\
\hline $17^{\circ} 34^{\prime} \mathrm{S}$ & 41 & 42 & 3 & 0.98 & 19 & 14 & $1.36^{*}$ & 0.46 & 0.33 & 5.95 & 6.32 & 5.97 & 7.83 & 8.47 \\
\hline $18^{\circ} 25^{\prime} \mathrm{S}$ & 68 & 62 & 2 & 1.10 & 17 & 8 & $2.13^{*}$ & 0.25 & 0.13 & 4.99 & 4.84 & 4.92 & 7.11 & 7.92 \\
\hline $21^{\circ} 25^{\prime} \mathrm{S}$ & 23 & 21 & 2 & 1.10 & 7 & 4 & $1.75^{*}$ & 0.30 & 0.19 & 6.00 & 5.86 & 5.91 & 9.11 & 9.65 \\
\hline $21^{\circ} 33^{\prime} \mathrm{S}$ & 13 & 19 & 0 & $0.68^{*}$ & 9 & 5 & $1.80^{*}$ & 0.69 & 0.26 & 7.44 & 7.23 & 7.31 & 8.38 & 10.22 \\
\hline Total Biospeedo'04 & 244 & 236 & 15 & 1.03 & 85 & 59 & $1.44^{*}$ & 0.35 & 0.25 & 5.63 & 5.90 & 5.75 & 7.69 & 8.36 \\
\hline
\end{tabular}

The proportion of juveniles (3\%) and mature individuals (around $25 \%$ of the total number of females) were close to those observed at $13^{\circ} \mathrm{N} / \mathrm{EPR} 2 \mathrm{yr}$ apart. Nevertheless, the proportion of mature females varied between 13 and $39 \%$ across latitudinal samples (Table 2). The size of females at first sexual maturity corresponds to $5.80 \mathrm{~mm}$, and is not different from the value found at $13^{\circ} \mathrm{N} / \mathrm{EPR}$. The size of males at first sexual maturity is quite a bit smaller $(2.90 \mathrm{~mm})$ than that of females. With the exception of $17^{\circ} 24^{\prime} \mathrm{S}$, mature females were always bigger than mature males at each site, and a significant difference in the proportion of mature males and females was found in favour of males $\left(\chi^{2}\right.$ test; $\left.\mathrm{p}>0.05\right)$.

Male and female size distributions obtained from the whole $13^{\circ} \mathrm{N} / \mathrm{EPR}$ and SEPR collections are shown in Fig. 2. Distributions are similar in shape between genders and between collections concerning the number and the position of the modal components, the third containing only mature individuals. KolmogorovSmirnov 2-sample tests showed no significant statistic difference between male and female distributions of NEPR ( $p>0.10)$ and SEPR ( $p>0.10)$, but no significant difference between cruises either $(p>0.10)$. However, discrepancies can be found among size-frequency histograms associated with local populations. Indeed, as shown in Fig. 3, populations from the vent chimneys Parigo, Rehu Marka

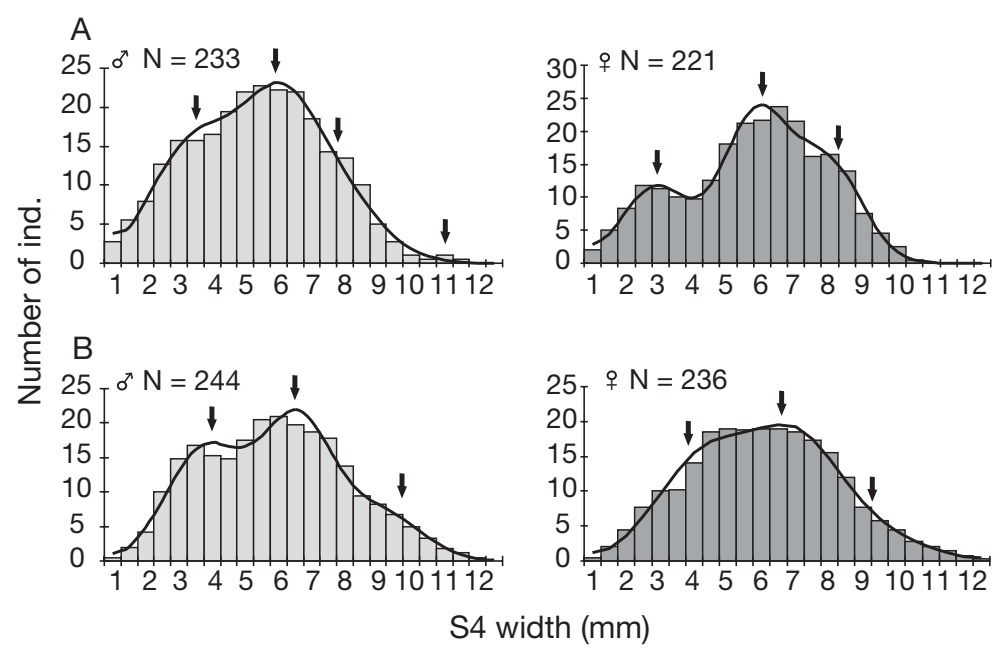

Fig. 2. Alvinella pompejana. Size-frequency histograms of males (light grey) and females (dark grey) over the whole $A$. pompejana collection sampled: (A) at $13^{\circ} \mathrm{N}$ on the East Pacific Rise (EPR) during the Phare'02 cruise and (B) over the southern EPR during the Biospeedo'04 cruise. Curve: theoretical admixtures calculated by MIX 3.13; arrows: modal position of cohort; N: number of individuals; S4: 4th setigerous segment 

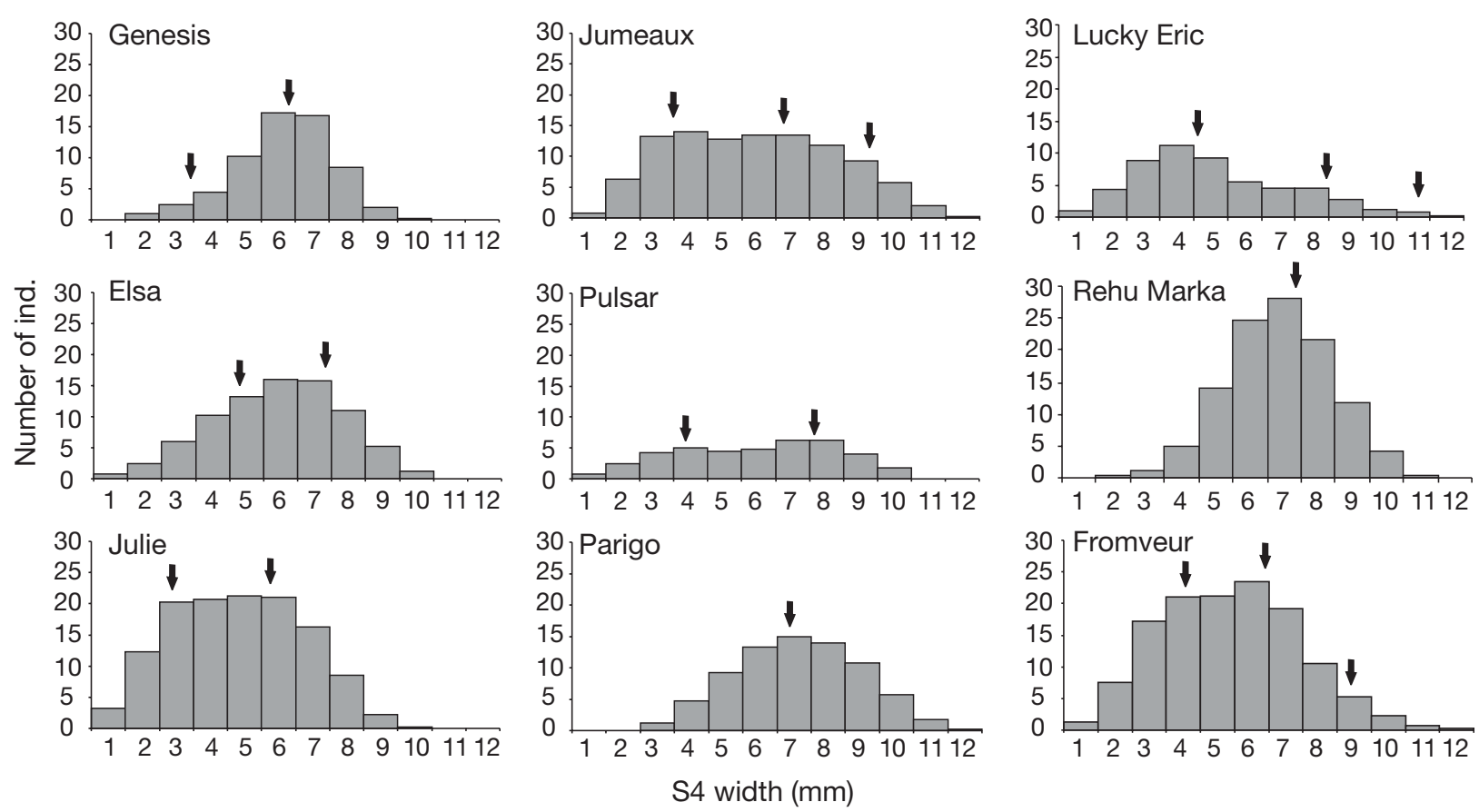

Fig. 3. Alvinella pompejana. Subsample of 9 size-frequency distributions for which individuals were the most numerous (6 vent sites at $13^{\circ} \mathrm{N}$ on the East Pacific Rise [EPR]: Genesis, Elsa, Julie, Jumeaux, Pulsar and Parigo; 3 vent sites on the southern EPR: at $13^{\circ} 58^{\prime} \mathrm{S}$ [Lucky Eric]; at $17^{\circ} 24^{\prime} \mathrm{S}$ [Rehu Marka]; at $18^{\circ} 25^{\prime} \mathrm{S}$ [Fromveur]). Discrepancies between histograms may be an indication of the recruitment heterogeneity according to peculiar dynamics conditions occurring locally (currents or vent activity). Arrows: modal position of cohort

and Genesis lacked at least 1 size group. This supports the hypothesis of a spatial heterogeneity in larval recruitment, survival, or individual growth rate.

Synchronisation of recruitment at a local scale $\left(13^{\circ} \mathrm{N} / \mathrm{EPR}\right)$

Size-frequency distributions and modal decompositions have been performed for samples containing at least 50 ind. (i.e. Elsa, Genesis, Julie, Jumeaux, Pulsar and Parigo) (Table 3). Note that temporal samples collected (max. $10 \mathrm{~d}$ apart) at the vent sites Elsa and Parigo (see Table 1) were pooled together after a MannWhitney $U$-test indicating no difference between the temporal distributions $(U=458.5, \mathrm{p}=0.847$ and $U=$ 565.5, $\mathrm{p}=0.0738$, respectively). The number of modal components varies according to locality: only 1 size group was found at Parigo, 2 at Elsa, Genesis and Julie and 3 at Jumeaux. A Kruskal-Wallis test indicated that localities differ significantly in distribution $(H=49.677$, $\mathrm{df}=7, \mathrm{p}<0.0001)$. An a posteriori test, however, clearly showed that samples are not grouped according to the sampling date. Such spatial heterogeneity in distributions contradicts the assumption of recruitment synchrony at a field scale. However, synchronisation may be masked by differences in individual growth rates and mortality between sites or by differences in larval settlement over the $13^{\circ} \mathrm{N} / \mathrm{EPR}$ field. The similarity of modal values within each component however indicates that differences in distribution are more likely due to a lack of some components at some locations and, thus, discrepancies in recruitment (Table 3, Fig. 3).

\section{Synchronisation of recruitment at a regional scale}

(SEPR)

Size-frequency distributions and modal decompositions have been performed for the whole fields and over each vent sector for $13^{\circ} 58^{\prime}, 17^{\circ} 24^{\prime}, 17^{\circ} 34^{\prime}$ and $18^{\circ} 25^{\prime} \mathrm{S}$, and by pooling worms coming from $21^{\circ} 25^{\prime}$ and $21^{\circ} 33^{\prime} \mathrm{S}$ (Table 3 ). As previously observed within the vent sector $13^{\circ} \mathrm{N} / \mathrm{EPR}$, the number of modal components varies according to vent sectors: at least only 1 or 2 size groups (out of 3 ) occur at $17^{\circ} 24^{\prime}$ and $17^{\circ} 34^{\prime} \mathrm{S}$, respectively, whereas 3 modes can be identified for all other vent sectors. The unique modal value of the sample from $17^{\circ} 24^{\prime} \mathrm{S}$ is $6.40 \mathrm{~mm}$, which corresponds to Size group 2 of the other samples and suggests either an absence of recent recruitment in this sector or a spatial discrimination between adults and juveniles at this particular site. A 1-way ANOVA was performed to compare modal positions for Size groups 1, 2 and 3 
Table 3. Alvinella pompejana. Modal decomposition of sizefrequency distributions of the 4 th setigerous segment width within samples collected at northern $\left(13^{\circ} \mathrm{N}\right)$ and southern East Pacific Rise (EPR). The modal decomposition was performed using MIX 3.1 software (McDonald \& Green 1988). $\mathrm{n}$ : number of individuals collected

\begin{tabular}{|c|c|c|}
\hline Vent site & Proportion & Mean $\pm \mathrm{SD}(\mathrm{mm})$ \\
\hline \multicolumn{3}{|c|}{ Northern EPR } \\
\hline \multicolumn{3}{|c|}{ Elsa $\left(\mathrm{p}=0.9990 ; \chi^{2}=0.380 ; \mathrm{df}=6 ; \mathrm{n}=82\right)$} \\
\hline \multirow[t]{3}{*}{ Component } & 0.58 & $4.40 \pm 1.6$ \\
\hline & 0.42 & $6.83 \pm 1.18$ \\
\hline & - & - \\
\hline \multicolumn{3}{|c|}{ Genesis $\left(\mathrm{p}=0.9997 ; \chi^{2}=0.258 ; \mathrm{df}=13 ; \mathrm{n}=63\right)$} \\
\hline \multirow[t]{3}{*}{ Component } & 0.08 & $2.70 \pm 0.75$ \\
\hline & 0.92 & $5.90 \pm 1.21$ \\
\hline & - & - \\
\hline \multicolumn{3}{|c|}{ Julie $\left(\mathrm{p}=0.9995 ; \chi^{2}=0.297 ; \mathrm{df}=6 ; \mathrm{n}=126\right)$} \\
\hline \multirow[t]{3}{*}{ Component } & 0.42 & $2.62 \pm 1.07$ \\
\hline & 0.58 & $5.54 \pm 1.36$ \\
\hline & - & - \\
\hline \multicolumn{3}{|c|}{ Jumeaux ( $\left.p=0.9862 ; \chi^{2}=0.143 ; \mathrm{df}=3 ; \mathrm{n}=103\right)$} \\
\hline \multirow[t]{3}{*}{ Component } & 0.26 & $2.70 \pm 0.89$ \\
\hline & 0.58 & $5.75 \pm 1.69$ \\
\hline & 0.16 & $8.70 \pm 1.08$ \\
\hline \multicolumn{3}{|c|}{ Pulsar $\left(\mathrm{p}=0.9999 ; \chi^{2}=0.138 ; \mathrm{df}=6 ; \mathrm{n}=40\right)$} \\
\hline \multirow[t]{3}{*}{ Component } & 0.44 & $3.28 \pm 1.37$ \\
\hline & 0.56 & $7.12 \pm 1.31$ \\
\hline & - & - \\
\hline \multicolumn{3}{|c|}{ Parigo $\left(\mathrm{p}=0.9951 ; \chi^{2}=1.724 ; \mathrm{df}=9 ; \mathrm{n}=77\right)$} \\
\hline \multirow[t]{3}{*}{ Component } & $1-1$ & - \\
\hline & 1 & $6.64 \pm 1.80$ \\
\hline & 3 & - \\
\hline \multicolumn{3}{|c|}{ Southern EPR } \\
\hline \multicolumn{3}{|c|}{$13^{\circ} 58^{\prime} \mathrm{S}\left(\mathrm{p}=1.0000 ; \chi^{2}=1.705 ; \mathrm{df}=17 ; \mathrm{n}=57\right)$} \\
\hline \multirow[t]{3}{*}{ Component } & 0.70 & $3.52 \pm 1.18$ \\
\hline & 0.28 & $7.31 \pm 1.18$ \\
\hline & 0.02 & $11.00 \pm 1.18$ \\
\hline \multicolumn{3}{|c|}{$17^{\circ} 24^{\prime} \mathrm{S}\left(\mathrm{p}=1.0000 ; \chi^{2}=1.712 ; \mathrm{df}=17 ; \mathrm{n}=93\right)$} \\
\hline \multirow[t]{3}{*}{ Component } & - & - \\
\hline & 1.00 & $6.40 \pm 1.33$ \\
\hline & - & - \\
\hline \multicolumn{3}{|c|}{$17^{\circ} 34^{\prime} \mathrm{S}\left(\mathrm{p}=1.0000 ; \chi^{2}=3.195 ; \mathrm{df}=18 ; \mathrm{n}=86\right)$} \\
\hline \multirow[t]{3}{*}{ Component } & 0.39 & $3.76 \pm 1.44$ \\
\hline & 0.61 & $7.36 \pm 1.55$ \\
\hline & - & - \\
\hline \multicolumn{3}{|c|}{$18^{\circ} 25^{\prime} \mathrm{S}\left(\mathrm{p}=0.9907 ; \chi^{2}=5.735 ; \mathrm{df}=16 ; \mathrm{n}=132\right)$} \\
\hline \multirow[t]{3}{*}{ Component } & 0.45 & $3.31 \pm 1.10$ \\
\hline & 0.46 & $5.80 \pm 1.10$ \\
\hline & 0.08 & $8.40 \pm 1.10$ \\
\hline \multicolumn{3}{|c|}{$21^{\circ} 25-33^{\prime} \mathrm{S}\left(\mathrm{p}=1.0000 ; \chi^{2}=2.206 ; \mathrm{df}=18 ; \mathrm{n}=78\right)$} \\
\hline \multirow[t]{3}{*}{ Component } & 0.45 & $4.17 \pm 1.11$ \\
\hline & 0.30 & $7.01 \pm 1.11$ \\
\hline & 0.25 & $9.79 \pm 1.11$ \\
\hline
\end{tabular}

between vent fields of the SEPR. This test showed no significant differences among modal values for Size Group 1, 2, or 3 respectively, $F=0.09$, p $>0.05 ; F_{\mathrm{C}}=0.32$, $\mathrm{p}>0.05 ; F=1.98, \mathrm{p}>0.05)$, suggesting that local recruitments may be more or less synchronised along the ridge axis over $15^{\circ}$ of latitude when they occurred.

\section{Reproduction dynamics in Alvinella pompejana}

\section{Reproductive stages}

The high number of modal decompositions that have been performed (98 females: 20000 measured oocytes) and the constancy of the modal standard deviation across the oocyte cohorts $(12 \mu \mathrm{m})$ allowed us to discriminate 5 oocyte maturation stages in Alvinella pompejana populations according to the number of oocyte cohorts (1 to 5), with decreasing numbers of gametes (Fig. 4).

\section{Fecundity range}

Female fecundity varies greatly among individuals and mainly depends on the maturation stage of the female. Females with 1 oocyte cohort have an average number of 5810 oocytes, 2-cohort females have 28900 oocytes, 3-cohort females have 35330 oocytes and 4cohort females have 135112 oocytes. Reproductive females with 5 oocyte cohorts display 200319 oocytes on average, which is higher than the counts by Desbruyères et al. (1998). However, reproductive females with 5 cohorts have high but very unequal fecundities that range from 67000 to about 978000 oocytes. All females having empty oviducts present $<5$ cohorts and very low fecundities. The number of oocytes, as expected, slightly increases with body size, but this trend is not significant $\left(\mathrm{R}^{2}=0.149, \mathrm{p}>0.05\right)$. Furthermore, there is no statistic correlation between body size and mean oocyte diameter when analyzing the 2 collections (NEPR, SEPR) of mature females (see Fig. 5A, B). A significant positive relationship $\left(R^{2}=0.442, p<0.01\right)$ was reported between mean oocyte diameter and number of oocyte 'cohorts' found in the coelom (Fig. 6).

\section{Asynchrony of oocyte maturation between females}

Oocyte maturation stages are not spatially or temporally synchronised. The proportions of these stages do not seem to be correlated with the increasing size of the worm and do appear to be heterogeneous among the collected samples (Table 4). Within a given size group, some females appear to begin oogenesis when others are active spawners. The occurrence of distinct oocyte maturity stages among females throughout samples may be a good indicator of a continuous breeding system in this peculiar polychaete. However, reproductive females having 5 oocyte 'cohorts' represent the most frequent reproductive stage found in maturing females, suggesting that oogenesis is probably very fast. Simultaneous observations of oviducts 


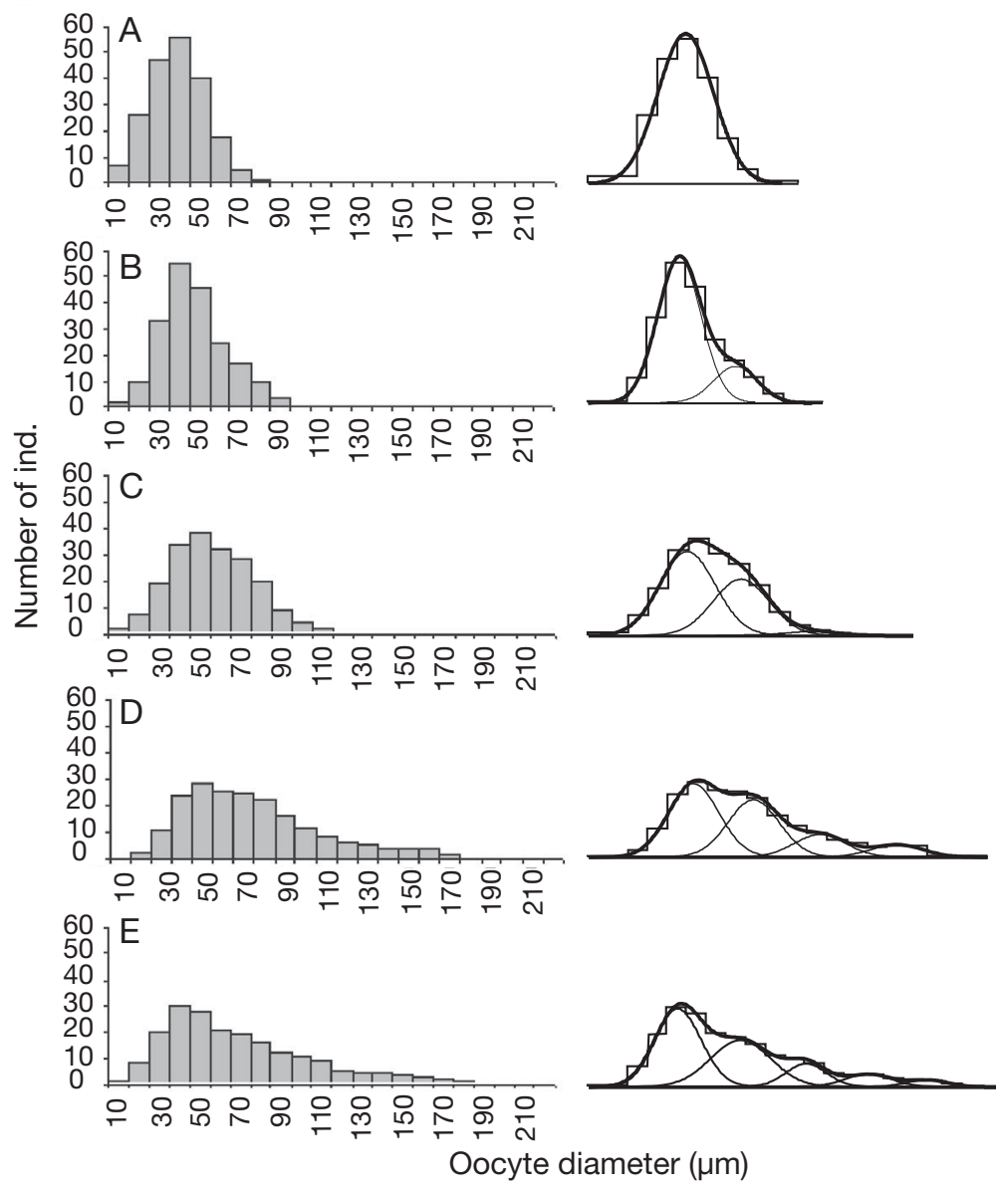

Fig. 4. Alvinella pompejana. Presentation of the 5 female maturity stages (mature to reproductive), with oocyte size-frequency distribution (left) and their modal decomposition (right) in Cohorts 1 to 5 (A to $\mathrm{E}$, respectively)

between modal positions of these 2 subsequent 'cohorts' within the $13^{\circ} \mathrm{N} / \mathrm{EPR}$ vent field (first cohort: $F_{\mathrm{C}}=0.08, \mathrm{p}>0.05$; second cohort: $\left.F_{\mathrm{c}}=0.22, \mathrm{p}>0.05\right)$. A similar test performed on the oocyte distributions of females that came from 2 hydrothermal vents $<50 \mathrm{~km}$ away from each other $\left(17^{\circ} 24^{\prime}\right.$ and $\left.17^{\circ} 34^{\prime} \mathrm{S}\right)$ did not show a significant difference either (first cohort: $F_{\mathrm{C}}=$ $0.08, \mathrm{p}>0.05$; second cohort: $F_{\mathrm{C}}=0.16, \mathrm{p}>$ 0.05), suggesting that spawning could be synchronised at a vent sector scale (Fig. 7). On the other hand, this may also be an indication of continuous gametogenesis, in which dynamics are insensitive to locality or sampling date.

\section{Variation of oocyte distributions at the regional scale (SEPR)}

The extensive sampling of Alvinella pompejana from $7^{\circ} 24^{\prime}$ to $21^{\circ} 33^{\prime} \mathrm{S}$ along the SEPR allowed us to test the hypothesis of a latitudinal shift of reproduction in A. pompejana. In order to discriminate between a latitudinal effect and a time effect, the chronology of the vent field sampling did not correlate with latitude (see Table 1). Therefore, a 1-way ANOVA test was performed using modal positions of oocyte 'cohorts' as variables and females as replicates within each vent field. Modal means and related standard

and coelomic fluid showed that some large females initiated oogenesis (none to 1 single cohort of 20 to $50 \mu \mathrm{m}$ oogonia) while they still had $200 \mu \mathrm{m}$ mature oocytes in their oviducts.

\section{Variation of oocyte distributions within vent sectors}

Although mature females exhibit some asynchrony in their reproductive state, discontinuous recruitment as expected from demography could still be explained by the synchronisation of spawning events. According to this hypothesis, oocyte cohorts are expected to be synchronised among all females over the whole process of oogenesis. We therefore tested this hypothesis under the assumption of a constant maturation rate of oocytes. Modal positions were compared between females within the vent sectors $13^{\circ} \mathrm{N} / \mathrm{EPR}$ and $17^{\circ} \mathrm{S} /$ EPR only for the first 2 oocyte 'cohorts' for which a sufficient number of individuals was available. A 1-way ANOVA shows that there is no significant difference deviations are presented in Fig. 8 as a scatterbox graph. Although populations were separated by 100 s of $\mathrm{km}$, the only significant difference was detected for Cohort $1(F=4.59, \mathrm{p}<0.01)$. For Cohorts 2, 3, 4 and 5, differences were not significant ( $p>0.05)$, indicating a great reproductive homogeneity across mature females over the whole EPR.

Table 4. Alvinella pompejana. Distribution of female reproductive stages in latitudinal samples collected along the southern East Pacific Rise

\begin{tabular}{|llllrrr|}
\hline & \multicolumn{6}{c|}{ Number of oocyte cohorts } \\
& 1 & 2 & 3 & 4 & 5 & Total \\
\hline $13^{\circ} \mathrm{N}$ & 1 & 0 & 1 & 6 & 17 & 25 \\
$7^{\circ} \mathrm{S}$ & 0 & 0 & 0 & 3 & 2 & 5 \\
$13^{\circ} \mathrm{S}$ & 0 & 0 & 0 & 1 & 3 & 4 \\
$17^{\circ} \mathrm{S}$ & 1 & 2 & 1 & 4 & 20 & 28 \\
$18^{\circ} \mathrm{S}$ & 0 & 1 & 2 & 1 & 4 & 8 \\
$21^{\circ} \mathrm{S}$ & 2 & 0 & 0 & 3 & 4 & 9 \\
Total & 4 & 3 & 4 & 18 & 50 & 79 \\
\hline
\end{tabular}



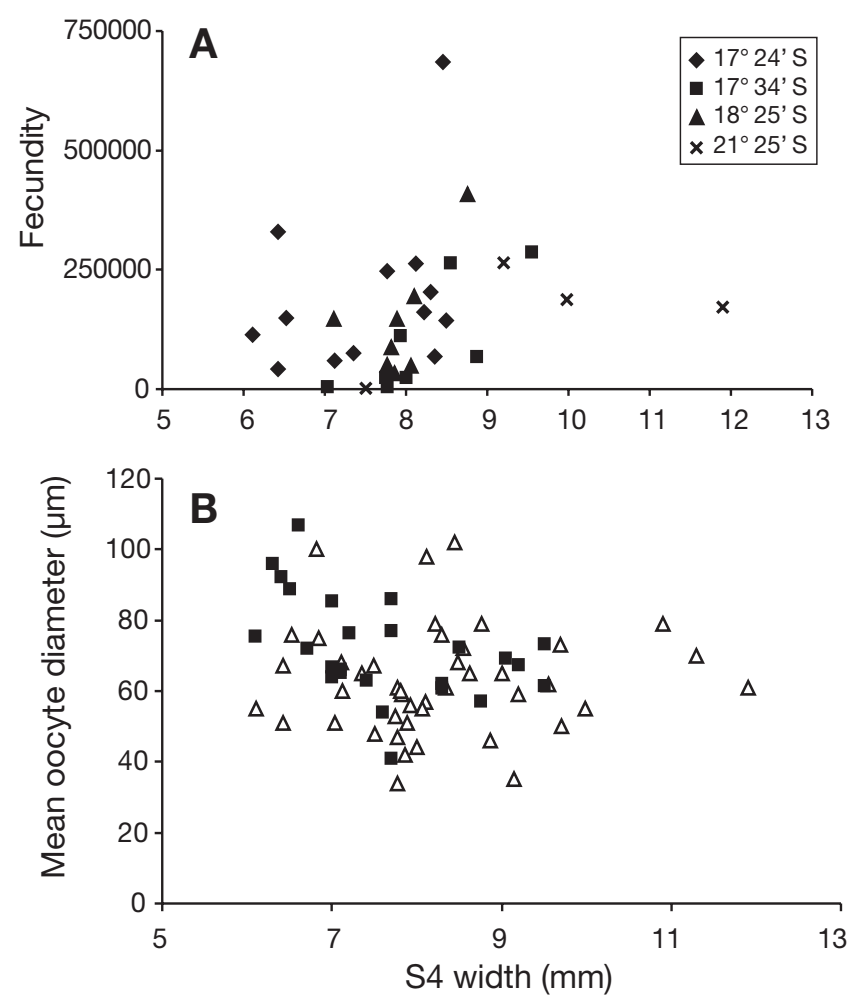

Fig. 5. Alvinella pompejana. (A) Positive but not significant relationship between female fecundity and female S4 width. (B) Negative but non-significant relationship between mean oocyte diameter and size of female ( $\mathrm{S} 4$ width) ( $\mathrm{N}=54$ females). Filled symbols: females from Phare'02; open symbols: females from Biospeedo'04. Note different $x$-axis scales

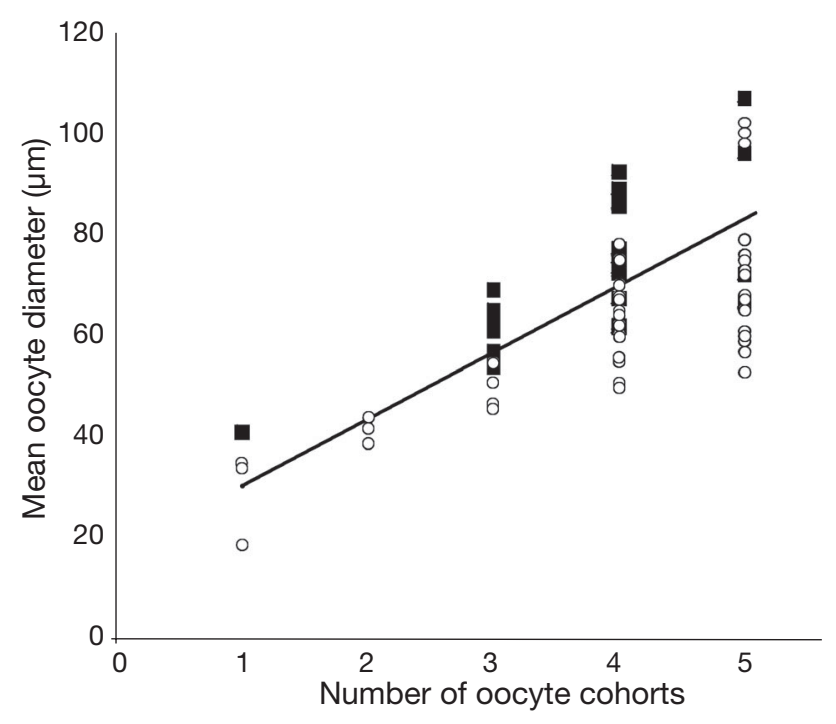

Fig. 6. Alvinella pompejana. Positive relationship between mean oocyte diameter $(\mu \mathrm{m})$ and female 'reproductive' stage (represented by the number of oocyte cohorts) ( $\mathrm{N}=54$ mature females, $y=9.703 x+26.916, \mathrm{R}^{2}=0.442 ; \mathrm{p}<0.01$ ). Filled symbols: females from Phare'02; open symbols: females from Biospeedo'04

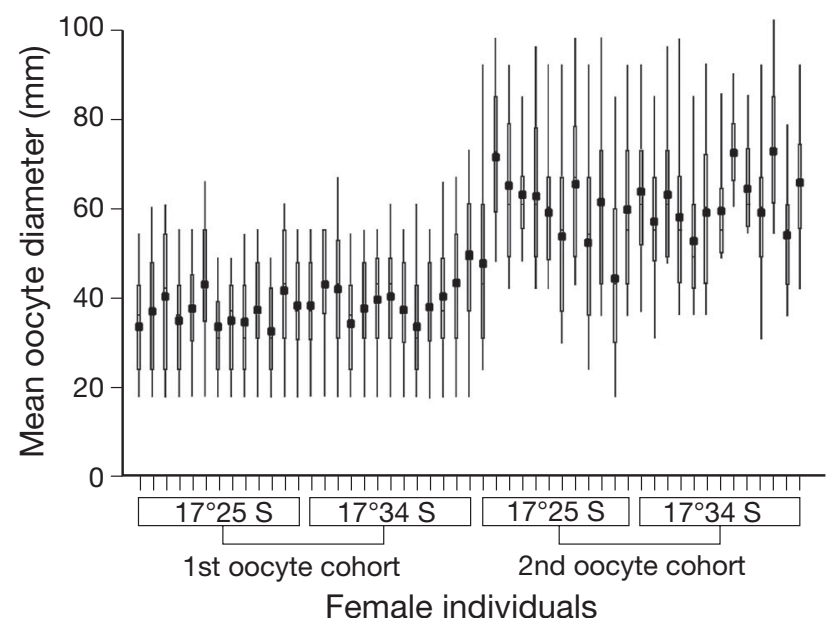

Fig. 7. Alvinella pompejana. Scatterbox showing the modal oocyte diameter per ind. together with minima, maxima and $\mathrm{SD}$ for the first 2 oocyte cohorts of all the mature females of A. pompejana collected at the 2 vent fields $17^{\circ} 24^{\prime}$ and $17^{\circ} 34^{\prime} \mathrm{S}$ on the East Pacific Rise

A multiple linear regression with latitude, the female S4 width and the sampling date as explicative variables was conducted on the first oocyte modal position. This analysis showed only a significant decrease in oocyte diameter with the sampling date (Table 5). A graphic representation of the oocyte diameter against the sampling date suggests that the decrease in oocyte diameter (oogonia renewal) may be cyclic (Fig. 9).

\section{Short-term evolution of the Totem population}

Despite an extensive effort to sample the Totem population, our analyses could only be conducted on small sample sizes: 48 worms (16 February 1996) and 6 worms (18 March 1996). From modal decompositions of size-frequency histograms, 2 distinct size groups were found at each date (Table 6). A Student's $t$-test

Table 5. Equation parameters $(b, t)$ and associated statistics (P-perm) of the multiple linear regression of the first oocyte cohort across females of Alvinella pompejana collected along the southern East Pacific Rise. Explicative variables correspond to latitude, sampling date and S4 width

\begin{tabular}{|lrrl|}
\hline Variable & $b$ & $t$ & P-perm \\
\hline Intercept & 42.572 & 9.093 & \\
Latitude & 0.218 & 0.437 & 0.340 \\
Date & -0.312 & -3.213 & $0.001^{*}$ \\
S4 width & -0.059 & -0.349 & 0.379 \\
$\mathrm{R}^{2}=0.19038$ & $F=3.84069$ & $0.0150^{*}$ \\
Number of permutations: 999 & \\
\hline
\end{tabular}




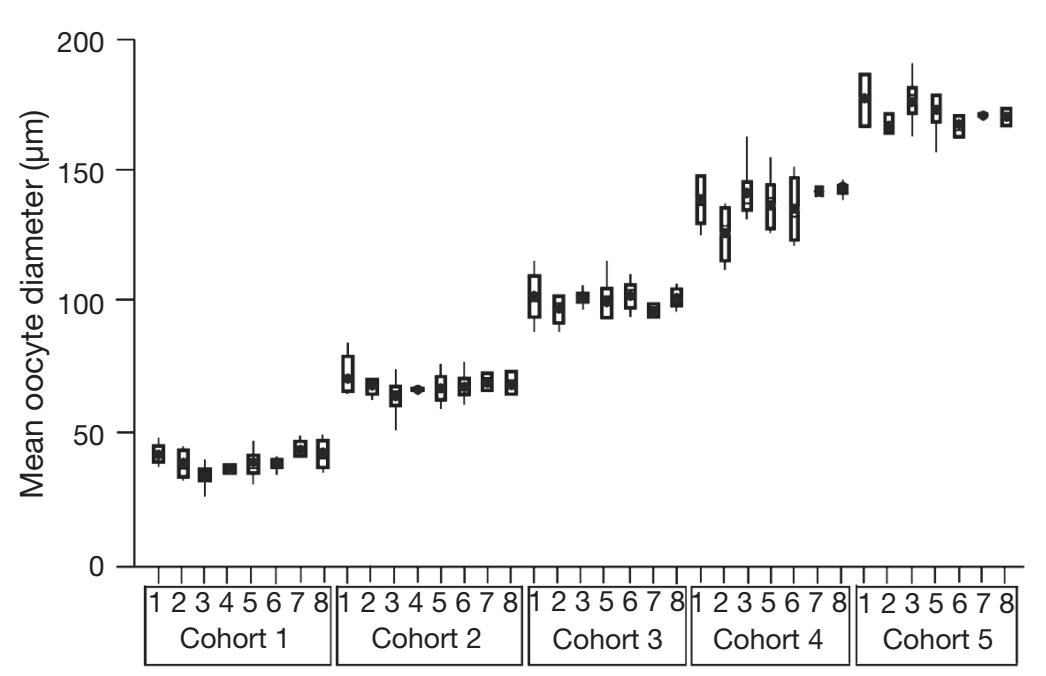

Population

Fig. 8. Alvinella pompejana. Scatterbox showing the mean oocyte diameter across females of $A$. pompejana from each population together with minima, maxima and SD for the 5 oocyte cohorts. Numbers (vent fields) $-1: 7^{\circ} 25^{\prime} \mathrm{S}_{\text {; }}$ 2: $13^{\circ} 58^{\prime} \mathrm{S}_{;} 3: 17^{\circ} 24^{\prime} \mathrm{S}_{;} 4: 17^{\circ} 25^{\prime} \mathrm{S}_{;} 5$ : $17^{\circ} 34^{\prime} \mathrm{S} ; 6: 18^{\circ} 25^{\prime} \mathrm{S}_{;} 7: 21^{\circ} 25^{\prime} \mathrm{S}_{;} 8: 21^{\circ} 33^{\prime} \mathrm{S}$

\section{DISCUSSION}

\section{Sex ratio, effective population size and mature male excess}

Alvinella pompejana is a tubedwelling worm which lives in a highly patchy and unstable environment. The life span of alvinellid chimneys is likely within the order of a decade, and the cessation of activity causes the death of most associated fauna (Tunnicliffe 1991). To endure local extinction, $A$. pompejana appears to have adapted to these vent conditions through a strategy that maximises reproductive success and subsequent effective dispersal. An equilibrate sex ratio of $1: 1$ is the most effective way to maximise the reproductive effort, providing that partners have an equal chance to mate, which is often associated with an internal mode of fertilisation in annelids (Giangrande 1997).

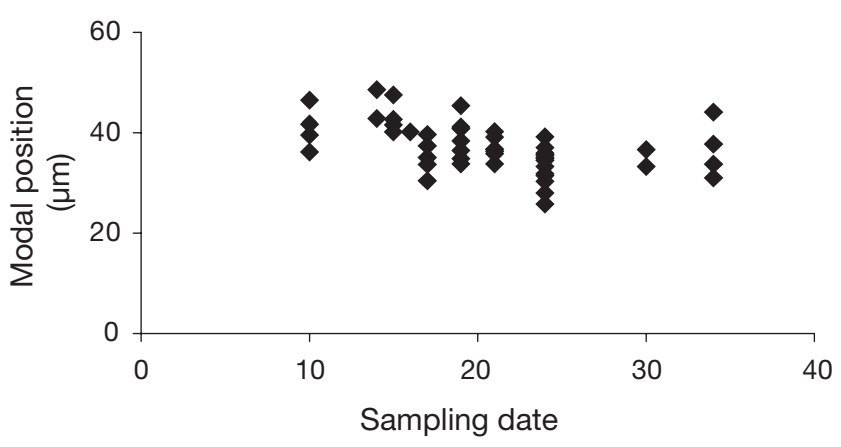

Fig. 9. Alvinella pompejana. Relationship between the modal position of the first oocyte cohort and the sampling date (in days since the beginning of the Biospeedo'04 cruise)

comparison of the modal positions between the 2 samples was found to be statistically significant ( $t=2.423$, $\mathrm{df}=43, \mathrm{p}<0.0 .05)$ and highly significant $(t=4.26, \mathrm{df}=$ 64, $\mathrm{p}<0.01$ ) for Modal components 1 and 2, respectively. Modal differences between the 2 temporal samples could be attributable to the ageing of the cohorts, but also to migration, sampling impact, or small-scale environmental heterogeneity.

The temporal evolution of oocyte maturation was followed by examining 10 females and 9 females at each date, respectively. MFodal values averaged over females resulting from the decomposition of sizefrequency histograms suggested a tiny shift in oocyte maturation (Table 6). A comparison of these modal values using a $t$-test reveals, however, no significant difference.
In A. pompejana, although balanced when considering the overall population, the sex ratio appears to be significantly biased towards males in the breeding population (i.e. mature individuals). Increasing the number of reproductive males against reproductive females would decrease the effective population size (Hartl 1988), and thus is likely to become detrimental for the

Table 6. Alvinella pompejana. Modal value means of the oocyte diameter across females for each oocyte 'cohort' between temporal samples collected subsequently, $31 \mathrm{~d}$ apart at the vent site Totem $\left(13^{\circ} \mathrm{N} / \mathrm{EPR}\right)$

\begin{tabular}{|c|c|c|}
\hline & Modal position & $\mathrm{SD}$ \\
\hline \multicolumn{3}{|c|}{ Dive 106 (16 Feb 1996) } \\
\hline \multicolumn{3}{|c|}{ Width (mm) } \\
\hline 1 & 3.60 & 1.57 \\
\hline 2 & 8.57 & 1.70 \\
\hline \multicolumn{3}{|c|}{ Oocyte diameter $(\mu \mathrm{m})$} \\
\hline 1 & 40.09 & 6.38 \\
\hline 2 & 70.25 & 10.48 \\
\hline 3 & 119.86 & 14.61 \\
\hline 4 & 156.69 & 6.47 \\
\hline 5 & 180.82 & 3.87 \\
\hline \multicolumn{3}{|c|}{ Dive 1088 (18 Mar 1996) } \\
\hline \multicolumn{3}{|c|}{ Width (mm) } \\
\hline 1 & 2.72 & 1.67 \\
\hline 2 & 7.32 & 1.67 \\
\hline \multicolumn{3}{|c|}{ Oocyte diameter $(\mu \mathrm{m})$} \\
\hline 1 & 38.46 & 6.03 \\
\hline 2 & 59.82 & 5.07 \\
\hline 3 & 97.03 & 11.68 \\
\hline 4 & 144.70 & 12.00 \\
\hline 5 & Absent & Absent \\
\hline
\end{tabular}


species over evolutionary time. To understand whether an excess of reproductive males could be beneficial for the species, one needs to consider that $A$. pompejana is a gonochoric species that uses internal fertilisation to reproduce (Chevaldonné \& Jollivet 1993). Females possess a pair of oviducts that are both connected to a spermathecae in which spermatozoids are stored and which opens as a unique genital pore (Pradillon \& Gaill 2003). The presence of spermathecae in females allows them to be fertilised by several males and, even more, to be inseminated while they are still immature. A specific case of immature insemination of females has already been reported for the coastal polychaete Dinophilus gyrocilliatus (Westheide 1990). During the Biospeedo' 04 cruise, this hypothesis was confirmed by the discovery of a young immature female that was already inseminated (i.e. presence of spermatozoids inside the spermatheca). As a consequence, a sex-ratio bias in favour of reproductive males represents an obvious adaptive advantage, as it increases the probability that females become fertilised as early as possible and by $>1$ male. Such a reproductive strategy has already been described in species with very small population sizes, which mate more often in order to increase the effective population's size (Wilson 1963). The maintenance of genetic diversity is favoured and can be highly beneficial for a species that endures recurrent population extinctions and possible founder effects. Previous in situ observations indeed showed that newly formed chimneys are usually recolonised by very few young individuals (Chevaldonné 1996). In such patches all individuals are immature and non-reproductive. A similar situation has been described for the early successional stages of the Northeast Pacific alvinellid Paralvinella palmiformis (Copley et al. 2003). Reproductive mechanisms whereby global genetic diversity is maintained despite recurrent population bottlenecks that decrease the effective population size may have been an adaptive response to the vent conditions over time. Because this kind of reproductive mode has also been reported for other hydrothermal vent polychaetes (Paralvinella grasslei: Zal et al. 1994, Branchipolynoe seepensis: McHugh \& Tunnicliffe 1994, Jollivet et al. 2000) in which spermathecae are present and pseudo-copulation occurs, one can propose that this kind of reproductive mode has been selected by polychaetes in unstable and ephemeral habitats such as hydrothermal vents, as it increases the reproductive success of the species and promotes genetic diversity in small populations.

\section{Population structure and recruitment dynamics}

Size-frequency distributions of the worms combined across localities for each cruise are quite similar in shape and dominated by the medium-sized individuals. A refined analysis of the observed global distributions together with those obtained within each locality, however, clearly indicated that they significantly depart from normal distribution with a regular polymodal structure where modal values are equally spaced. Following modal decompositions, nearly all populations are characterised by 3 size groups, which correspond to immature individuals, individuals that possess fully developed genital tracts and reproductive individuals. Reproductive females always have the largest sizes, whereas reproductive males can also be found in the second size group. Such observations favour the hypothesis of regular arrivals of recruits inside populations. Conversely, the fact that very few immature individuals are usually found in the samples, coupled with the observation that size histograms are the same independent of the latitude and sampling date, is a strong argument in favour of a low but semicontinuous settlement of individuals. From our dataset we can therefore propose that Alvinella pompejana exhibits a semi-continuous mode of recruitment, where frequent pulses of settlers are likely to provide the observed distributions. This assumption however relies upon the hypothesis that young A. pompejana have a very fast growth rate and rapidly reach $\mathrm{Co}-$ hort 2, where they accumulate. The dominance of Cohort 2 reflects a decrease in growth rate, a high mortality rate, a short life duration of the worm, or a bad sampling technique. Although numerous factors could be involved to explain the short-term variations of demographic structures at Totem (e.g. migration, smallscale environmental heterogeneity), the shift between modal peaks of the subsequent temporal distribution could reflect a high growth rate of individuals.

\section{Oocyte distributions and reproduction dynamics}

The modal decomposition of oocyte-size histograms showed the presence of 1 to 5 discrete oocyte cohorts according to the reproductive state of the animal, displaying a log-normal decrease in abundance from oogonia to mature oocytes. The smallest mature females were characterised by a single cohort of smallsized oocytes ( 20 to $40 \mu \mathrm{m}$ ), whereas the largest mature females displayed 5 distinct and equally spaced cohorts of oocytes. These latter females were the only ones to present mature oocytes $(180 \mu \mathrm{m})$ inside their oviducts and, thus, the only ones able to spawn. The examination of numerous oocyte distributions and their cross-comparison provided no doubt about the quality of the modal decomposition, with modal positions of the oocyte cohorts equidistant and with constant standard deviations. Consequently, this kind of 
oocyte distribution first suggests periodic short-term pulses in the oocyte production with a linear growth rate of oocyte maturation until recruitment in the oviducts is completed. This assumption is strengthened by the fact that reproductive stages are positively correlated with oocyte size. Together with the fact that no more than 4000 mature oocytes can accumulate inside both oviducts before each spawning, regularly spaced oocyte cohorts could be indicative of a reproduction pattern with discrete and regular spawning events. However, the fact that reproductive stages are not synchronised in females among populations is a strong argument in favour of semi-continuous reproduction in Alvinella pompejana. Most populations indeed display a variable proportion of each reproductive stage even if the highest proportion of reproductive females corresponds to the 5-cohort stage (i.e. females able to spawn). In polychaetes, most continuous reproducers exhibit non-synchronised gametogenic stages across individuals within populations (Giangrande 1997).

The log-normal shape of the oocyte size distributions is, however, very surprising and poses an intriguing question about the decreasing number of oocytes in each 'cohort' during maturation. Similar observations have been obtained on the deep-sea ice worm Hesiocaeca methanicola and have been explained as an artefact due to organism damage or partial spawning during fixation (Eckelbarger et al. 2001). This, however, was not the case for A. pompejana, as females were stressed but alive and still intact prior to dissection and oviducts prevented animals from expelling coelomic oocytes outside.

The oocyte size-frequency distributions with a lot of small oocytes $(>100000)$ and only a few observed in the oviducts (4000) suggest that most oogonia are not able to reach their final stage of maturation in the coelom. Because no degenerating oocyte has been found in $>10000$ oocyte measurements, the death of a large number of oogonia during the maturation process is unlikely. We propose that the decrease in oocyte numbers from the beginning of synthesis to oviduct recruitment within each female could reflect: (1) a very fast growth rate of individuals, (2) different rates of oogenesis and vitellogenesis, or (3) endogenous hormones that control the maturation process in order to fuel the oviducts on demand (i.e. transfer of $x$ mature oocytes in oviducts implies the maturation of $x$ oogonia in the coelom). The second idea relies on the fact that oogenesis is rapid and continuous while vitellogenesis is a slow process. Oocyte production is then a function of the animal size, so that the number of oocytes produced increased continuously over time. Therefore, smaller oocytes should be found in much higher numbers than larger oocytes. Such a hypothesis fits well with the occurrence of a yolk autosynthesis mode of production, which alternatively indicates a low oocyte maturation rate (Eckelbarger 1994). The third idea relies on the fact that the massive stock of oogonia in the coelom can be viewed as a vitelline reserve that would secure the full development of a small subset of ovocytes via nurse or 'helper' cells (Eckelbarger 1986). However, Pradillon \& Gaill (2003) previously showed that vitellogenesis is achieved inside the coelomic cavity without 'helper' cells via autosynthetic mechanisms of yolk production.

\section{Spawning and recruitment synchrony over large spatial scales}

The polymodal nature of size histograms for both individual worms and oocytes suggests that spawning and recruitment are non-continuous and possibly periodic, at least over short periods of time. Discontinuous recruitment has been reported for nearly all hydrothermal vent species examined so far (Tyler \& Young 1999), especially vent polychaetes (McHugh 1989, Zal et al. 1995, Copley et al. 2003), and has led to the hypothesis that external factors such as tidal cycles or food source seasonality must synchronise the recruitment by pulses. By contrast, most reproductive characteristics of Alvinella pompejana, like the co-occurrence of all reproductive stages in various proportions within each population, support the hypothesis of semi-continuous reproduction. Nevertheless, the lack of significant differences in the modal position of oocyte sizes suggests that females may be highly synchronised within and between hydrothermal vent fields at the ridge scale, despite their heterogeneity in reproductive stages. In this case, discrete spawning events may occur within a short time interval. Although we did not detect great variation in oocyte modal diameters between females from SEPR vent fields, multiple regression analysis of the first modal cohort between females indicated a significant decrease in oocyte diameter with time. These results suggest that a periodic signal in oocyte maturation may occur in females, possibly in response to regular pulses of spawning. This observation is in agreement with the occurrence of periodic settlement peaks in populations and the shift of oocyte modes observed between temporal samples collected during Hot'96. Although nearly continuous, the reproductive cycle can be partly influenced by environmental factors, such as the lunar cycle, as previously stated by Chevaldonné et al. (1991), Zal et al. (1995) and Copley et al. (1999).

Based on this present dataset, we propose that Alvinella pompejana has 2 contrasting life phases: a rapid growth phase during the early benthic phase and an 
intense reproductive phase with frequent spawning events later. In the second phase, most of the energy may be allocated to gamete production. The largest specimens could correspond to reproductive individuals of different age classes and reproductive stages as described for the deep-sea ophiuroids (Gage \& Tyler 1991). Such a hypothesis may explain why no positive relationship between the size of the worm and its reproductive stage or oocyte diameter was found. Consequently, oocyte diameter or female maturity stage may possibly reflect the age of the worm in a better way than the individual size.

Size-frequency histograms displayed a great heterogeneity in the number of modal components within and between vent fields. This is mainly due to the lack of, at least, one size group within specific samples. As an example, the sample at $17^{\circ} 34^{\prime} \mathrm{S} / \mathrm{EPR}$ was only composed of small and large individuals. By contrast, the sample from the nearby vent field at $17^{\circ} 24^{\prime} \mathrm{S}$ only displayed medium-sized individuals. The presence of a large number of immature individuals at the former site clearly indicated the arrival of new recruits at the chimney, although they were totally absent at the latter site. Such an observation suggests that: (1) local vent dynamics may occasionally prevent the settlement and recruitment at a given site or (2) larval supply may only be episodic and occasionally prevent local recruitment according to hydrodynamic constraints. Furthermore, size heterogeneity of modal components among localities can be explained by variation in the growth rate of females in habitats.

\section{CONCLUSIONS}

Based on our study, Alvinella pompejana displays several population and reproductive features: (1) a 1:1 sex ratio but a shift in sexual maturity between genders, (2) a very high fecundity reaching 200000 oocytes on average, (3) a heterogeneity in maturation state of individuals within populations and (4) reproduction dynamics that follow a semi-continuous breeding pattern with short-term synchrony. Like other hydrothermal vent polychaetes, polymodal demographic structures are characteristic of A. pompejana. While this kind of structure is generally associated with discontinuous and synchronised reproduction, the limited number of juveniles in populations and the temporal and spatial similarities of size histograms between cruises and localities suggested the frequent arrival of a limited number of recruits within populations, followed by a fast growth rate among recruits and accumulation of individuals in the adult cohort.

Morphological adaptations of the reproductive apparatus, such as oviducts and spermathecae, and semi- continuous oogenesis reinforce the idea that these reproductive peculiarities could have recently evolved in response to the unstable nature of the vent habitat, in order to maximise reproductive success and maintain genetic diversity. Because some of these characteristics are shared between most hydrothermal polychaetes (Zal et al. 1994, Copley et al. 2003, Hilario et al. 2005), we propose that they represent a recent adaptive convergence to vent patchiness and instability, in order to minimise the extinction risk for the species.

Acknowledgements. We gratefully acknowledge the captains and crews of the RV 'Nadir' and RV 'Atalante', and the pilots and co-pilots of the 'Nautile' team. We are particularly grateful to F. Gaill and N. LeBris, chief scientists of the Hot'96 and Phare'02 cruises, who allowed us to conduct this work. We thank the 3 anonymous referees for their very valuable comments on the first draft of the manuscript. This work was partially founded by the Région Bretagne (contrat Accueil \& Emergence).

\section{LITERATURE CITED}

Anderson MJ, Legendre P (1999) An empirical comparison of permutation methods for tests of partial regression coefficients in a linear model. J Stat Comput Simulation 62: 271-303

Bhattacharya CG (1967) A simple method of resolution of adistribution into Gaussian component. Biometric 23:115-135

Chevaldonné P (1996) Ecologie des cheminées hydrothermales actives. Thèses de doctorat, Université de la Méditerranée Aix-Marseille

Chevaldonné P, Jollivet D (1993) Videoscopic study of deepsea hydrothermal vent alvinellid polychaete populations: biomass estimation and behaviour. Mar Ecol Prog Ser 95: 251-262

Chevaldonné P, Desbruyères D, Le Haître M (1991) Timeseries of temperature from three deep-sea hydrothermal vent sites. Deep-Sea Res 38:1417-1430

Chevaldonné $P$, Jollivet $D$, Vangriesheim $A$, Desbruyères $D$ (1997) Hydrothermal-vent alvinellid polychaete dispersal in the eastern Pacific. I. Influence of vent site distribution, bottom currents and biological patterns. Limnol Oceanogr 42:67-80

Copley JTP, Tyler PA, Murton BJ, Van Dover CL (1997) Spatial and interannual variation in the faunal distribution at Broken Spur vent field $\left(29^{\circ} \mathrm{N}\right.$, Mid-Atlantic Ridge). Mar Biol 129:723-733

Copley JTP, Tyler PA, Van Dover CL, Schultz A, Dickson P, Singh SM, Sulanowska M (1999) Subannual temporal variation in faunal distribution at the TAG hydrothermal mound $\left(26^{\circ} \mathrm{N}\right.$, Mid-Atlantic Ridge). PSZNI Mar Ecol 20: 291-306

Copley JTP, Tyler PA, Van Dover CL, Philip SJ (2003) Spatial variation in the reproductive biology of Paralvinella palmiformis (Polychaeta: Alvinellidae) from a vent field on the Juan de Fuca Ridge. Mar Ecol Prog Ser 255:171-181

Desbruyères D, Chevaldonné $\mathrm{P}$, Alayse AM, Jollivet D and 14 others (1998) Biology and ecology of the 'Pompeii worm' (Alvinella pompejana Desbruyères and Laubier), a normal dweller of an extreme deep-sea environment: a synthesis of current knowledge and recent developments. DeepSea Res II 45:383-422 
Eckelbarger KJ (1983) Evolutionary radiation in polychaete ovaries and vitellogenic mechanisms: their possible role in life history patterns. Can J Zool 61:487-504

Eckelbarger KJ (1986) Vitellogenic mechanisms and the allocation of energy to offspring in polychaetes. Bull Mar Sci 39:426-443

Eckelbarger KJ (1994) Diversity of metazoan ovaries and vitellogenic mechanisms: implications for life history theory. Proc Biol Soc Wash 107:193-218

Eckelbarger KJ, Young CM, Ramirez Llodra E, Brooke S, Tyler P (2001) Gametogenesis, spawning behavior, and early development in the 'iceworm' Hesiocaeca methanicola (Polychaeta: Hesionidae) from methane hydrates in the Gulf of Mexico. Mar Biol 138: 761-775

Frontier S, Pichod-Viale D (1998) Ecosystèmes: structure, fonctionnement, évolution. Masson, Paris

Gage JD, Tyler PA (1991) Deep sea biology: a natural history of organisms at the deep-sea floor. Cambridge University Press, Cambridge

Giangrande A (1997) Polychaete reproductive patterns, life cycles and life histories: an overview. Oceanogr Mar Biol Annu Rev 35:323-386

Hartl DL (1988) A primer of population genetics, 2nd edn. Sinauer, Sunderland, MA

Hilario A, Young CM, Tyler PA (2005) Sperm storage, internal fertilisation, and embryonic dispersal in vent and seep tubeworms (Polychaeta: Siboglinidae: Vestimentifera). Biol Bull (Woods Hole) 208: 20-28

Jollivet D (1993) Distribution et évolution de la faune associée aux sources hydrothermales profondes à $13^{\circ} \mathrm{N}$ sur la dorsale du Pacifique oriental: le cas particulier des polychètes Alvinellidae, Vol 1. Thèses de doctorat, Université de Bretagne Occidentale, Brest

Jollivet D (1996) Specific and genetic diversity at deep-sea hydrothermal vents: an overview. Biodiversity Conserv 5: 1619-1653

Jollivet D, Chevaldonné P, Planque B (1999) Hydrothermalvent alvinellid polychaete dispersal in the eastern Pacific. II. A metapopulation model based on habitat shifts. Evolution 53:1128-1142

Jollivet D, Empis A, Baker MC, Hourdez S, Comtet T, JouinToulmond C, Desbruyères D, Tyler PA (2000) Reproductive biology, sexual dimorphism, and population structure of the deep sea hydrothermal vent scale-worm, Branchipolynoe seepensis (Polychaeta: Polynoidae). J Mar Biol Assoc UK 80:55-68

MacDonald PDM, Green PEJ (1988) Users guide to program MIX 2.3: an interactive program for fitting mixtures of distributions. Technical notes on Release 2.3. Ichtus Data Systems, Hamilton

McHugh D (1989) Population structure and reproductive biology of two sympatric hydrothermal vent polychaetes, Paralvinella pandorae and Paralvinella palmiformis. Mar Biol 103:95-106

McHugh D (1993) A comparative study of reproduction and development in the polychaete family Terebellidae. Biol Bull (Woods Hole) 185:153-167

Editorial responsibility: Howard Browman (Associate Editorin-Chief), Storebø, Norway
McHugh D, Tunnicliffe V (1994) Ecology and reproductive biology of the hydrothermal vent polychaete Amphisamytha galapagensis (Ampharetidae). Mar Ecol Prog Ser 106:111-120

Olive PJW (1970) Reproduction of a Northumberland population of the polychaete Cirratulus cirratus. Mar Biol 5: 259-273

Olive PJW (1984) Environmental control of reproduction in Polychaeta. Fortschr Zool 29:17-38

Pradillon F, Gaill F (2003) Oogenesis characteristics in the hydrothermal vent polychaete Alvinella pompejana. Invertebr Reprod Dev 43(3):223-235

Pradillon F, Zbinden M, Mullineaux LS, Gaill F (2005) Colonisation of newly-opened habitat by a pioneer species, Alvinella pompejana (Polychaeta: Alvinellidae), at East Pacific Rise vent sites. Mar Ecol Prog Ser 302:147-157

Sarrazin J, Juniper SK, Massoth G, Legendre P (1999) Physical and chemical factors influencing species distributions on a hydrothermal sulfide edifice of the Juan de Fuca Ridge, northeast Pacific. Mar Ecol Prog Ser 190: 189-112

Schroeder KC, Hermans CO (1975) Annelide: Polychaeta. In: Giese AC, Pearse JS (eds) Reproduction of marine invertebrates. Academic Press, New York

Shank TM, Fornari DJ, Von Damm KL, Lilley MD, Haymon RM, Lutz RA (1998) Temporal and spatial patterns of biological community development at nascent deep-sea hydrothermal vents ( $9^{\circ} 50^{\prime} \mathrm{N}$, East Pacific Rise). Deep-Sea Res II 45:465-515

Sokal RR, Rohlf FJ (1995) Biometry. The principles and practice of statistics in biological research, 3rd edn. Freeman, New York

Thiébaut E, Huther X, Shillito B, Jollivet D, Gaill F (2002) Spatial and temporal variations of recruitment in the tube worm Riftia pachyptila on the East Pacific Rise $\left(9^{\circ} 50^{\prime} \mathrm{N}\right.$ and $13^{\circ}$ N). Mar Ecol Prog Ser 234:147-157

Tunnicliffe V (1991) The biology of hydrothermal vents: ecology and evolution. Oceanogr Mar Biol Annu Rev 29: 319-407

Tyler PA, Young CM (1999) Reproduction and dispersal at vent and cold seeps. J Mar Biol Assoc UK 79:193-208

Westheide W (1990) Polychaetes: interstitial families. In: Kermarck DM, Barnes RSK (eds) Synopses of the British fauna, new series. Universal Book Services, Oegstgeest

Wilson EO (1963) Social modifications related to rareness in ant species. Evolution 17:249-253

Wilson WH (1991) Sexual reproductive modes in polychaetes: classification and diversity. Bull Mar Sci 48:500-516

Zal F, Desbruyères D, Jouin-Toulmond C (1994) Sexual dimorphism in Paralvinella grasslei, a polychaete annelid from deep-sea hydrothermal vents. C R Acad Sci Paris $317: 42-48$

Zal F, Jollivet D, Chevaldonné P, Desbruyères D (1995) Reproductive biology and population structure of the deep-sea hydrothermal vent worm Paralvinella grasslei (Polychaeta: Alvinellidae) at $13^{\circ} \mathrm{N}$ on the East Pacific Rise. Mar Biol 122:637-648

Submitted: December 4, 2006; Accepted: April 27, 2007 Proofs received from author(s): October 2, 2007 